\title{
Probing and Comparing the Photobromination and Photoiodination of Dissolved Organic Matter by Using Ultra-High-Resolution Mass Spectrometry
}

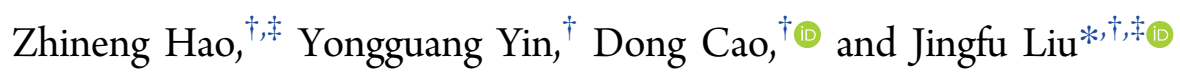

${ }^{\dagger}$ State Key Laboratory of Environmental Chemistry and Ecotoxicology, Research Center for Eco-Environmental Sciences, Chinese Academy of Sciences, P.O. Box 2871, Beijing 100085, China

${ }^{\ddagger}$ University of Chinese Academy of Sciences, Beijing 100049, China

\section{Supporting Information}

ABSTRACT: Photochemical halogenation of dissolved organic matter (DOM) may represent an important abiotic process for the formation of natural organobromine compounds (OBCs) and natural organoiodine compounds (OICs) within surface waters. Here we report the enhanced formation of OBCs and OICs by photohalogenating DOM in freshwater and seawater, as well as the noticeable difference in the distribution and composition pattern of newly formed OBCs and OICs. By using negative ion electrospray ionization coupled with Fourier transform ion cyclotron resonance mass spectrometry, various OBCs and OICs were identified during the photohalogenation processes in sunlit waters. The respective number of OBCs and OICs formed in artificial

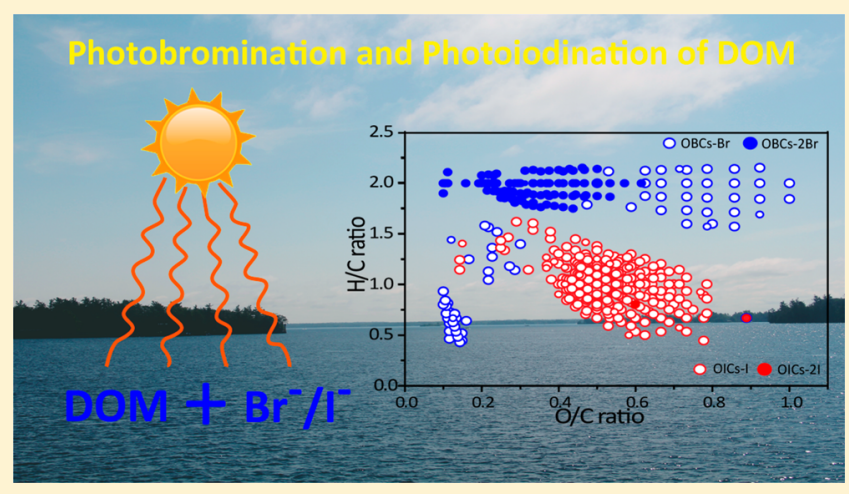
seawater (ASW) under light radiation was higher than that in artificial freshwater (AFW), suggesting a possible role of the mixed reactive halogen species. OBCs were formed mainly via substitution reactions and addition reactions accompanied by other reactions and distributed into three classes: unsaturated hydrocarbons with relatively low oxygen content, unsaturated aliphatic compounds, and saturated fatty acids and carbohydrates with relatively high hydrogen content. Unlike the OBCs, OICs were located primarily in the region of carboxylic-rich alicyclic molecules composed of esterified phenolic, carboxylated, and fused alicyclic structures and were generated mainly through electrophilic substitution of the aromatic proton. Our findings call for further investigation on the exact structure and toxicity of the OBCs and OICs generated in the natural environment.

\section{INTRODUCTION}

Natural organohalogen compounds, especially organobromine compounds (OBCs) and organoiodine compounds (OICs), have received increasing attention in recent years. The first reason is that they are ubiquitous in natural environments and can be produced through natural biotic and abiotic processes, which play an important role in the biogeochemical cycling of bromine and iodine. ${ }^{1-3}$ More importantly, OBCs and OICs can potentially cause adverse health effects, due to their higher cytotoxicity and genotoxicity as compared to their chlorinated analogues. $^{4-7}$ At present, approximately 2000 natural OBCs and 200 natural OICs have been identified, ${ }^{8,9}$ most of which are produced in marine environments, and the vast majority of these compounds are thought to originate from biological processes. $^{3,8-10}$ Only a few of the volatile OBCs and OICs, mainly involving the important atmospheric ozone-depleting gases (e.g., $\mathrm{CH}_{3} \mathrm{I}, \mathrm{CH}_{2} \mathrm{I}_{2}, \mathrm{CHClI}_{2}$, and $\mathrm{CHI}_{3}$ ), were considered to partially derive from abiotic pathways in natural environments. ${ }^{9,11,12}$ However, it seems that many more organohalogens may arise from abiotic pathways especially through nonspecific halogenation of dissolved organic matter (DOM), considering the covalent binding ability of bromine and iodine to DOM. ${ }^{13,14}$

Photochemical processing has the potential to produce organohalogen compounds within sunlit surface waters. For example, allyl alcohol and salicylic acid can be transformed into halogen-containing compounds during sunlight illumination. $^{15-17}$ It is believed that nonspecific halogenation of DOM by photochemically generated reactive halogen species (RHS) makes a significant contribution to the formation of a much wider variety of OBCs and OICs. ${ }^{18}$ The main reaction mechanisms are as follows: first, absorption of sunlight by DOM leads to the generation of reactive oxygen species (ROS) including hydroxyl radical $(\bullet \mathrm{OH})$, hydrogen peroxide $\left(\mathrm{H}_{2} \mathrm{O}_{2}\right)$, and DOM triplet state $\left({ }^{3} \mathrm{DOM}^{*}\right) .{ }^{19,20}$ Then bromide, iodide or

Received: August 17, 2016

Revised: $\quad$ March 6, 2017

Accepted: April 25, 2017

Published: April 25, 2017 
$\mathrm{IO}_{3}{ }^{-}$is oxidized/reduced by the DOM-induced ROS to form reactive halogen species (RHS). ${ }^{21-25}$ After that, RHS reacts with DOM to form OBCs and OICs via addition to unsaturated $\mathrm{C}-\mathrm{C}$ bonds, recombination with carbon-centered radicals, and/ or electrophilic substitution. ${ }^{12,25-30}$ However, to our knowledge, these researches failed to identify the products of photoinitiated DOM halogenation and to compare the differences between the newly formed OBCs and OICs, due in part to the difficulties in detecting the complexity and heterogeneity as well as the relatively low content of photohalogenated compounds.

Very recently, electrospray ionization (ESI) coupled to Fourier transform ion cyclotron resonance mass spectrometry (FT-ICR MS), an emerging ultra-high-resolution MS technique, has been applied in the characterization of the molecular composition of $\mathrm{DOM}^{31-35}$ and disinfection byproducts (DBPs) including chlorinated, brominated, and iodinated DOM. ${ }^{36-40}$ The objective of this study was to investigate photochemical generation of naturally occurring OBCs and OICs in artificial freshwater (AFW) and seawater (ASW) under sunlight irradiation. To this end, Suwannee River fulvic acid (SRFA) was selected as model DOM, and the photobromination of bromide-containing and photoiodination of iodide-containing AFW and ASW were conducted under simulated and natural sunlight irradiation, respectively. The newly formed OBCs and OICs were characterized by using FT-ICR MS, and the difference between the OBCs and OICs was compared. To our knowledge, this is the first work on identifying and characterizing the composition and distribution of photoinitiated OBCs and OICs in sunlit water environments by using FT-ICR MS.

\section{MATERIALS AND METHODS}

Chemicals and Materials. Suwannee River fulvic acid (SRFA) was purchased from the International Humic Substances Society (2S101F). Methanol (Optima grade) was purchased from Fisher Scientific Company (Shanghai, China). Potassium bromide and iodide (Guaranteed reagent) were purchased from Merck KgaA (Darmstadt, Germany) and Alfa Aesar Inc. (Shanghai, China), respectively. Ultrapure water (18.2 M $\Omega$ ) was prepared by a Milli-Q Gradient system (Millipore, Billerica, MA). Artificial seawater (ASW) was prepared according to the formula of Mendez-Diaz and Shimabuku (Table S1 in Supporting Information). ${ }^{18}$

Photochemical OBC and OIC Formation Experiments. The simulated experiments were performed in a solar simulator (Beifanglihui Co., SN-500, Beijing, China) equipped with three wind-refrigerated $2500 \mathrm{~W}$ xenon lamp to simulate the sunlight, and light was filtered by a $290 \mathrm{~nm}$ cutoff filter. The emission spectrum of the xenon lamp is shown in Figure S1, and the intensity of the light was maintained at $550 \mathrm{~W} \mathrm{~m}^{-2}$. Irradiation of aqueous samples ( $1 \mathrm{~L}$ ), containing $3.0 \mathrm{mg} \mathrm{C} / \mathrm{L}$ SRFA (as dissolved organic carbon, DOC), $25 \mu \mathrm{mol} \mathrm{L}{ }^{-1} \mathrm{Br}^{-}$(for AFW) or $0.8 \mathrm{mmol} \mathrm{L}^{-1} \mathrm{Br}^{-}$(for ASW) for photobromination, and 10 $\mu \mathrm{mol} \mathrm{L}{ }^{-1} \mathrm{I}^{-}$(for AFW and ASW) for photoiodination was carried out in magnetically stirred $1 \mathrm{~L}$ quartz glass bottles (10 $\mathrm{cm}$ inner diameter and $168 \mathrm{~cm}$ height) with quartz caps, and the path length was $12.7 \mathrm{~cm}$. A relatively high bromide ion concentration $\left(25 \mu \mathrm{mol} \mathrm{L}^{-1}\right.$ vs $\left.0-6.3 \mu \mathrm{mol} \mathrm{L}^{-1}\right)$ for freshwater and iodide ion concentration $\left(10 \mu \mathrm{mol} \mathrm{L}^{-1}\right.$ vs $\left.0-1 \mu \mathrm{mol} \mathrm{L}^{-1}\right)$ for freshwater and seawater were used to amplify brominated and iodinated products, facilitating the structure identification of newly formed OBCs and OICs by the FT-ICR MS. The $\mathrm{pH}$ was adjusted to $\sim 7.5$ with $5 \mathrm{mmol} \mathrm{L} \mathrm{L}^{-1}$ phosphate for freshwater, the temperature was controlled at $\sim 25{ }^{\circ} \mathrm{C}$ by water circulation, and the reaction time was up to 7 days. Dark control experiments were performed by wrapping the bottles with aluminum foil and repeating the same procedure.

The experiment under natural sunlight was carried out with the same procedures for 7 full days in mid-January, except that samples were exposed to solar irradiation without thermostatting (at an ambient temperature of $15{ }^{\circ} \mathrm{C}$ ) and the path length was $11.8 \mathrm{~cm}$. The weather conditions are listed in Table S2. All the bottles were placed on the roof of the Environmental Engineering Building, Kunming University of Science and Technology, China, at $24.9^{\circ} \mathrm{E}, 102.8^{\circ} \mathrm{N}$. The UVvis spectra and dissolved organic carbon (DOC) of samples before and after photohalogenation were recorded with a Shimadzu UV-vis-NIR spectrophotometer (UV-3600, Japan) and a Shimadzu total organic carbon analyzer (TOL, Japan), respectively.

Pretreatment of Water Samples for ESI-FT-ICR MS Analysis. After irradiation experiments were finished, all the samples were filtered with $0.45 \mu \mathrm{m}$ cellulose acetate membrane filters prior to extraction. Sample preconcentration and desalination were undertaken according to the general solidphase extraction (SPE) procedures adapted from MéndezDíaz ${ }^{18}$ and Dittmar. ${ }^{41}$ Briefly, water samples were acidified with $\mathrm{HCl}$ to $\mathrm{pH} \sim 2$ before loading, at a flow rate of $\sim 5 \mathrm{~mL} \mathrm{~min}^{-1}$, onto BondElut PPL solid-phase extraction (SPE) cartridges (6 $\mathrm{mL}, 1 \mathrm{~g}$, Agilent Technologies, Folsom, CA), which had been previously rinsed sequentially with methanol (two cartridge volumes) and acidified ultrapure water ( $\mathrm{pH} \sim 2$, two cartridge volumes). Then the cartridges were rinsed with at least two cartridge volumes of acidified ultrapure water for complete removal of salt, and the sorbents were dried with nitrogen gas. After that, each cartridge was eluted with two cartridge volumes of methanol. The eluate was subsequently freeze-dried and stored at $-20{ }^{\circ} \mathrm{C}$ in the dark for later analysis. The extraction efficiency of this SPE method for DOM compounds was around $60 \%$.

ESI-FT-ICR MS Analysis. Ultra-high-resolution mass spectra were acquired using a Bruker SolariX FT-ICR MS equipped with a $15.0 \mathrm{~T}$ superconducting magnet. Sample extract was diluted in $1 \mathrm{~mL}$ of 50:50 methanol/water (v/v) and continuously infused into the ESI unit using a syringe pump at a flow rate of $120 \mu \mathrm{L} \mathrm{h}^{-1}$. All samples were analyzed in negative ionization mode with broadband detection, and the ESI needle voltage was set to $-3.8 \mathrm{kV}$. Ions were accumulated in the hexapol ion trap for $0.2 \mathrm{~s}$ before being introduced into the ICR cell. Four M 32-bit data points were recorded per broadband mass scan, and the mass range was set at $\mathrm{m} / z 150-1000 \mathrm{Da}$. A total of 200 mass spectra were averaged per sample. The injection syringe and lines were washed three times with 50:50 methanol/water ( $\mathrm{v} / \mathrm{v})$ between each sample to minimize crosscontamination and any sample carryover. Blank methanol samples were run frequently and no carryover was observed, however, a number of $\mathrm{m} / z$ peaks always occurred and probably resulted from SPE resin or remaining contaminants in the solvent or instrument. The mass spectra were externally calibrated using $10 \mathrm{mmol} \mathrm{L}^{-1}$ of sodium formate solution and then internally recalibrated using a known homologous series of the SRFA. After internal recalibration, the instrument achieved excellent sensitivity with the mass error less than $0.2 \mathrm{ppm}$ over the entire mass range. For the sake of reliability, each sample was measured three times to test reproducibility. Peaks were 


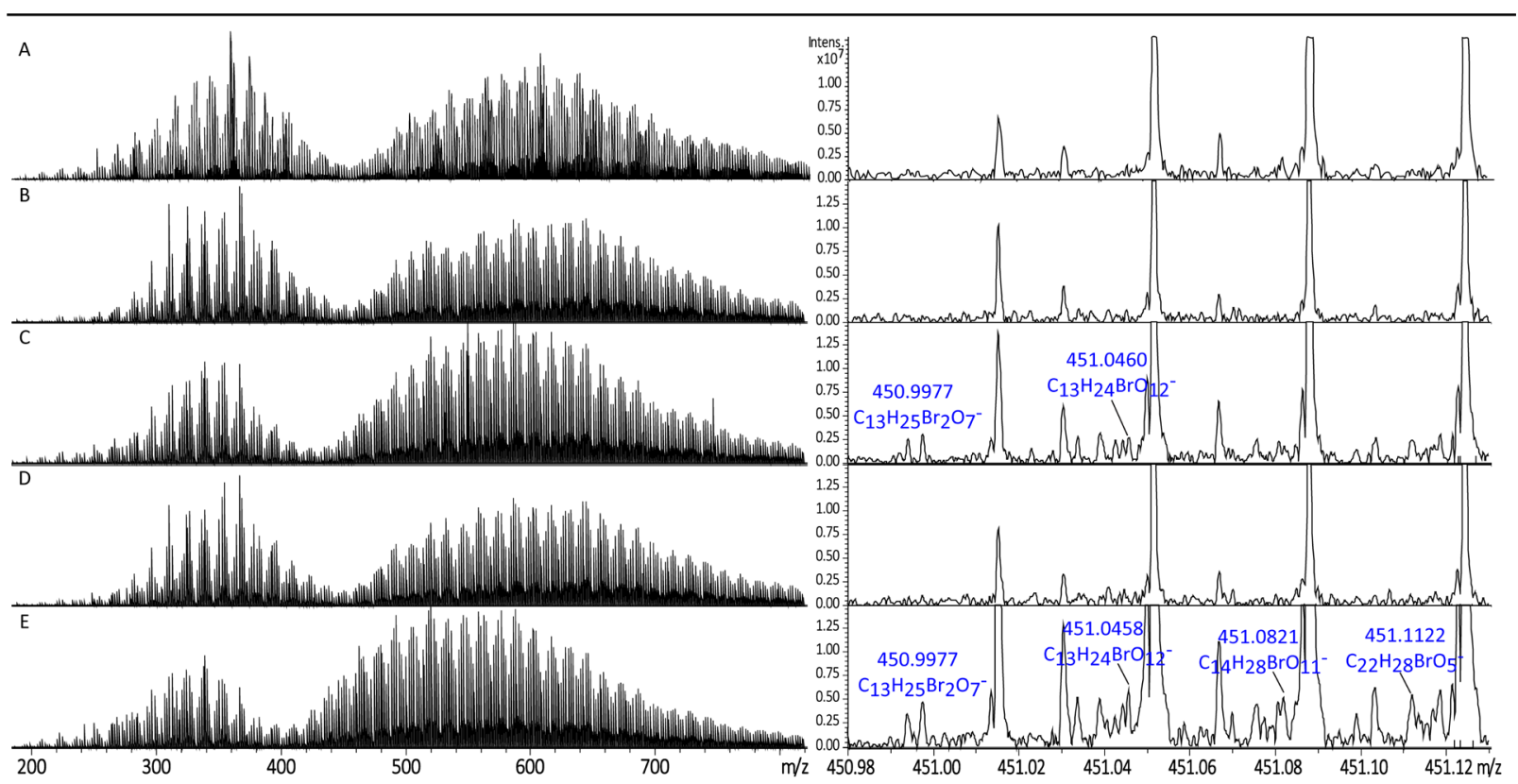

Figure 1. Negative-ion ESI-FT-ICR mass spectra of SRFA after $7 \mathrm{~d}$ of photochemical bromination under simulated sunlight radiation (left) and the OBCs at nominal mass $m / z 451$ (right). (A) The primary SRFA, (B) AFW control sample in darkness, (C) photobrominated AFW sample with Br ${ }^{-}$ $\left(25 \mu \mathrm{mol} \mathrm{L}{ }^{-1}\right)$, (D) ASW control sample in darkness, (E) photobrominated ASW sample with $\mathrm{Br}^{-}\left(0.8 \mathrm{mmol} \mathrm{L}^{-1}\right)$.

identified with Bruker Daltonics Data Analysis software version 4.0.

Molecular Formula Assignment. Software-based automated mass assignments were applied to quickly assign molecular formulas for most of the ions recorded, based on the criteria that the mass error between the measured and the calculated for a given chemical formula is $<1 \mathrm{ppm}$, and the signal-to-noise ratio $(\mathrm{S} / \mathrm{N})$ of mass peaks is $>4$. The following elements (and number of atoms of each element) were considered in the calculation: ${ }^{12} \mathrm{C}(1-100),{ }^{1} \mathrm{H}(1-200),{ }^{16} \mathrm{O}$ $(0-50),{ }^{35} \mathrm{Cl}(0-4),{ }^{79} \mathrm{Br}(0-3),{ }^{127} \mathrm{I}(0-3)$, and ${ }^{13} \mathrm{C}(0-1)$. The elemental ratios of $0.333 \leq \mathrm{H} / \mathrm{C} \leq 2.25$ and $0.1 \leq \mathrm{O} / \mathrm{C} \leq$ 1.0 were used as further restrictions for formula calculation. ${ }^{35}$ After the removal of unreasonable formulas, if several chemically and mathematically legitimate elemental formulas remained (usually small), the one that had the lowest deviation was chosen. The formulas above $500 \mathrm{Da}$ were assigned through the detection of homologous series. Due to the equal abundance of isotopes ${ }^{79} \mathrm{Br}$ and ${ }^{81} \mathrm{Br}$, isotope simulation was performed manually using the Bruker Daltonics Data Analysis software to cross-validate the assigned bromine-containing molecular formulas. ${ }^{42}$ Cluster analysis was conducted using SPSS software (IBM, Raleigh, NC) to present the MS differences among various experimental treatments. ${ }^{43}$

Because of the technical limitations and the complexity of DOM and halogenated photoproducts, it is very challenging to obtain the exact structures and compound groups. To reveal the composition and components of the halogenated photoproducts, all assigned formulas were classified into different structures and compound groups using the locations of the peaks based on the previous classical studies with certain assumption. $^{31,34,42-46}$ The common parameters and tools used to describe the locations of the peaks are as follows: Ultra-highresolution mass data were visually displayed according to the van Krevelen diagram; namely, the $\mathrm{H} / \mathrm{C}$ ratio was plotted against the $\mathrm{O} / \mathrm{C}$ ratio for all assigned molecular formulas. Kendrick plots including mass (KM) and Kendrick mass defect
(KMD) are useful to identify homologous molecular formula series that are spaced by $\mathrm{CH}_{2}$ groups. ${ }^{31,44}$ Here we used the modified Kendrick plot, in which unambiguous homologous series could be more easily identified. ${ }^{42,43}$ The modified aromaticity index (AI_mod) was calculated for formulas to estimate the fraction of aromatic and condensed aromatic structures. ${ }^{45}$ Furthermore, five groups relevant to our study were delineated in combination with AI_mod and $\mathrm{H} / \mathrm{C}$ cutoffs: $^{34,46}$ combustion-derived condensed polycyclic aromatics (AI mod >0.66), vascular plant-derived polyphenols $(0.66 \geq$ AI_mod $>0.50)$, highly unsaturated and phenolic compounds (AI_mod $\leq 0.50$ and $\mathrm{H} / \mathrm{C}<1.5$ ), aliphatic compounds $(2 . \overline{0}>\mathrm{H} / \mathrm{C} \geq 1.5)$, and saturated and carbohydrates $(\mathrm{H} / \mathrm{C}>2.0)$. The calculated parameters of assigned formulas are listed in Table S8.

As the photohalogenated products were generally formed via substitution reaction (SR) and addition reaction (AR), and the total number of relevant atoms of halogenated photoproducts was equal or proportionally more than the precursor compounds, the reaction type could be obtained by a comparison of the total number of relevant atoms for the molecular formula of the halogenated photoproducts with unhalogenated control samples. Specifically, in the identified OBCs and OICs, bromine and iodine were replaced by a hydrogen atom to revert the molecule to that containing only $\mathrm{C}, \mathrm{H}$, and $\mathrm{O}$. All compounds were thus grouped into three categories according to the reaction type: (i) SR between RHS and SRFA, presented both in the spectra of unbrominated or uniodinated control SRFA and photobrominated SRFA; (ii) AR between RHS and SRFA, presented in the spectra of photobrominated or photoiodinated SRFA but containing more hydrogen atoms or oxygen atoms in proportion to the number of $\mathrm{X}$ atoms (where $\mathrm{X}=\mathrm{Br}$ or $\mathrm{I}$ ) compared to the corresponding molecules of unhalogenated control SRFA; (iii) $\mathrm{SR}$ or AR accompanied by other reactions like photo-oxidation (SAOR). 


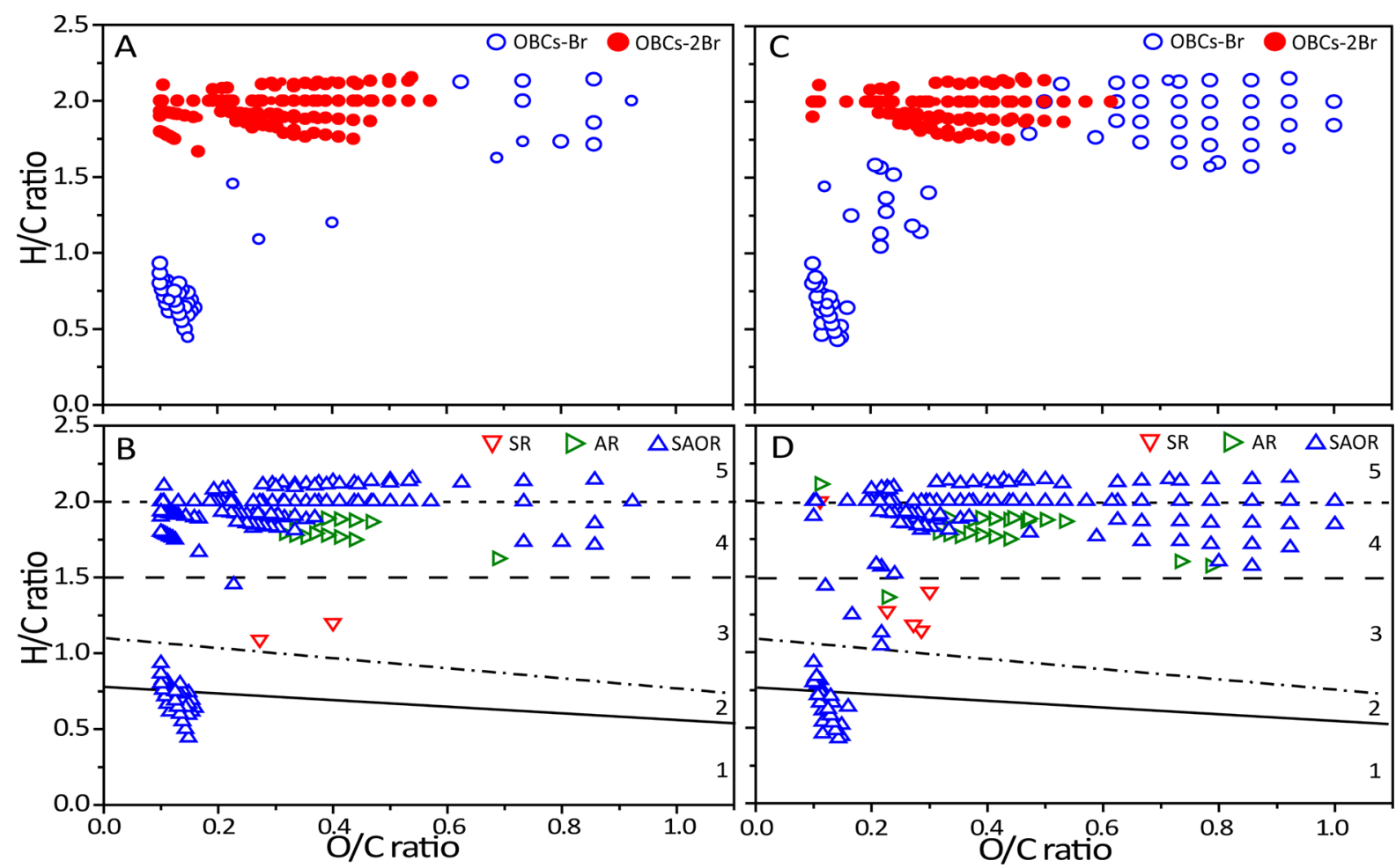

Figure 2. Molecular composition of OBCs of photobrominated AFW and ASW samples under simulated sunlight radiation. (A, C) van Krevelen diagram for OBCs in AFW and ASW samples, respectively. (B, D) van Krevelen diagram for OBCs in AFW and ASW sample formed via different reaction pathways, respectively. The bubble sizes for $\mathrm{A}$ and $\mathrm{C}$ represent the relative abundance of ions. Five groups in van Krevelen diagram are delineated by the modified aromaticity index (AI_mod) and H/C cutoffs: group 1 represents combustion-derived condensed polycyclic aromatics (AI_mod $>0.66$ ), group 2 represents vascular plant-derived polyphenols $(0.66 \geq \mathrm{AI}>0.50)$, group 3 represents highly unsaturated and phenolic compounds (AI_mod $\leq 0.50$ and $\mathrm{H} / \mathrm{C}<1.5)$, group 4 represents aliphatic compounds $(2.0 \geq \mathrm{H} / \mathrm{C} \geq 1.5)$, and group 5 represents saturated fatty and carbohydrates $(\mathrm{H} / \mathrm{C}>2.0)$. The $1,2,3,4$, and 5 in $\mathrm{B}$ and $\mathrm{D}$ represent groups $1,2,3,4$ and 5 , respectively.

\section{RESULTS AND DISCUSSION}

Sunlight-Driven Bromination of DOM in AFW and ASW. The photoinitiated ROS and DOM triplet state $\left({ }^{3} \mathrm{DOM}^{*}\right)$, formed by absorption of sunlight by DOM, facilitate the oxidation of bromide to reactive bromine species $(\mathrm{RBrS}),{ }^{22-24,47}$ which can then react with DOM to form various OBCs. In this study, many OBCs were detected with ESI-FT-ICR MS in the bromine-containing water under simulated and natural sunlight. The reproducibility tests showed that (i) the standard deviations of individual absolute peak heights were lower than $5 \%$, (ii) the average signal-tonoise ratio of the peaks denoting the OBCs and the following OICs was $>14$ and were indeed found in all triplicate spectra, and (iii) the proportion of peaks shared in the three measurements was $>70 \%$ (Table S3). This available evidence shows that ESI-FT-ICR MS spectra are reproducible and reliable when used to identify halogenated photoproducts. Figure 1 and Figure S2 show the ultra-high-resolution mass spectra of the SRFA of the dark control versus irradiated water and the close-up views of expanded mass spectra at the nominal mass $\mathrm{m} / z 451$ for OBCs, revealing the formation of large amount of OBCs. It should be noted that the poor shape and relative low intensity might be related to low content or low ion efficiency of the formed OBCs, which had a higher saturation or low content of oxygen (see below). Herein, for artificial freshwater (AFW), 155 and 57 OBCs were identified under simulated and natural sunlight irradiation, respectively. For artificial seawater (ASW), 164 and 122 OBCs were identified under simulated and natural sunlight irradiation, respectively
(Table S4). Except for the OBCs formed in ASW under natural sunlight irradiation, the major components were two brominecontaining OBCs (OBCs-2Br). Detailed molecular formulas for these OBCs are listed in Tables S8 and S9. In the replicated experiment of ASW photobromination under simulated sunlight irradiation, 155 OBCs were detected with a similar compositional distribution to previous results, indicating good reliability considering the change of instrument performance and other uncontrollable factors. It should be noted that in this study, 75 and 86 formulas of bromine-containing components were also identified in the dark AFW and ASW controls (Table S4), respectively, indicating that OBCs could be formed under a dark environment. This might be caused by the formation of $\mathrm{HO} \bullet$ upon oxidation of DOM in reduced state by $\mathrm{O}_{2}{ }^{48}$ and was supported by the observation of Méndez-Díaz ${ }^{18}$ that $\mathrm{O}_{2}$ likely participates in the formation of halogenated products. About 52 and 37 OBCs overlapped with the newly formed OBCs found in AFW and ASW under simulated light irradiation, and 20 and 7 of them overlapped under natural sunlight radiation. Among these overlapped OBCs in AFW, based on the measured peak intensities, the average of peak intensity increased by $20 \%$ and decreased by $12 \%$ after 7-day simulated and natural sunlight radiation. For ASW, the average peak intensity increased $46 \%$ and $17 \%$ after 7 -day simulated and natural solar radiation. Thus, it is rational to infer that environmental lighting could result in the generation and degradation of these OBCs. Interestingly, the OBCs newly produced in ASW under the light irradiation were more than that in AFW. This result suggests that the presence of seawater-level chloride ion is favorable for OBCs 


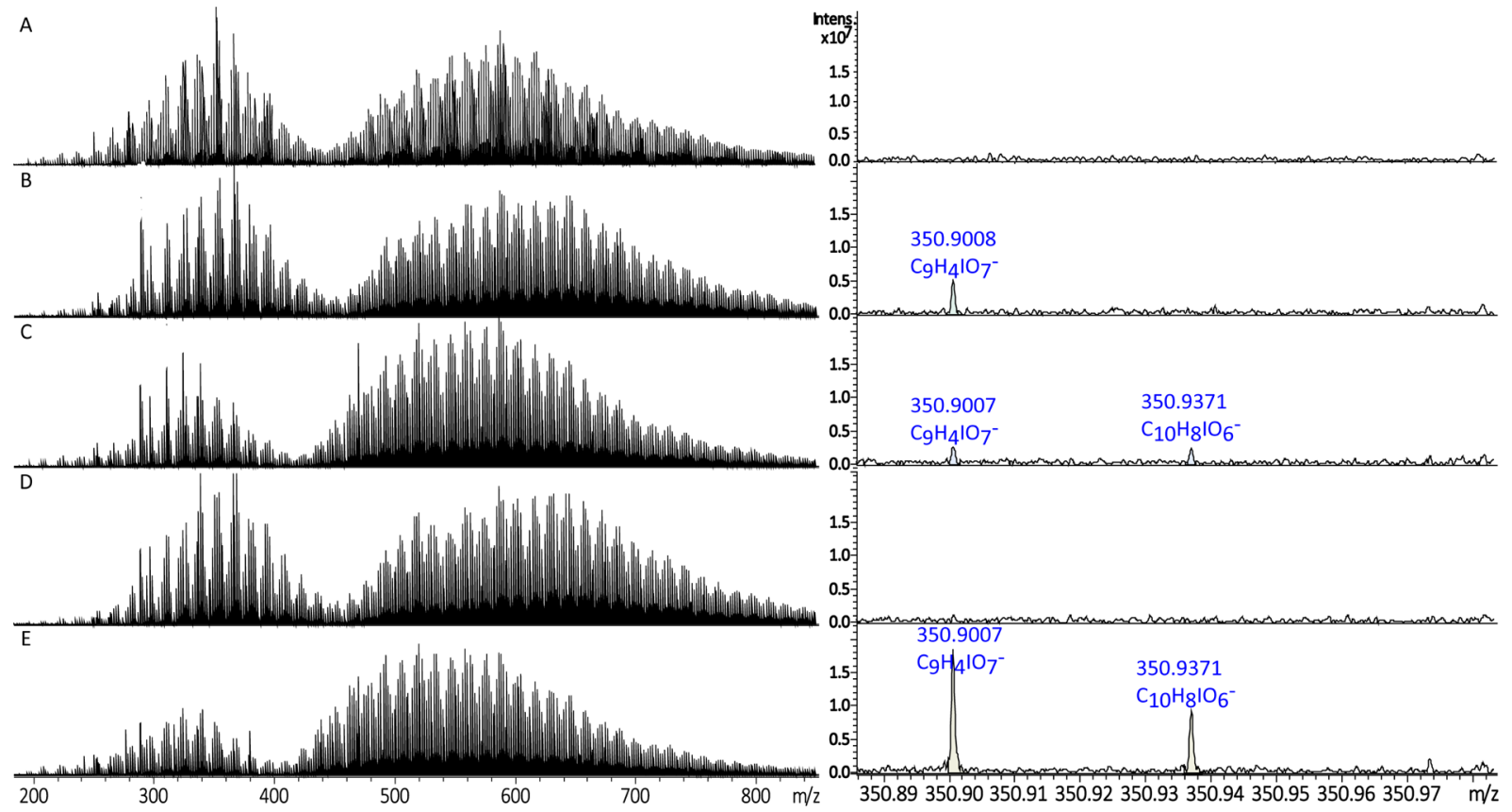

Figure 3. Negative-ion ESI-FT-ICR mass spectra of SRFA after $7 \mathrm{~d}$ of photochemical iodination under simulated sunlight radiation (left) and the OICs at nominal mass $m / z 351$ (right). (A) The primary SRFA, (B) AFW control sample in darkness, (C) photoiodinated AFW sample with $\mathrm{I}^{-}$(10 $\left.\mu \mathrm{mol} \mathrm{L}{ }^{-1}\right)$, (D) ASW control sample in darkness, (E) photoiodinated ASW sample with $\left.\mathrm{I}^{-}(10 \mu \mathrm{mol} \mathrm{L})^{-1}\right)$.

formation, indicating a possible role for mixed halogen species such as $\mathrm{BrCl}^{\bullet-}$ and/or $\mathrm{BrCl}^{18,47}$ during photohalogenation. This hypothesis was supported by the observation of mixed organohalogen compounds containing both bromine and chlorine (Table S7), of a change in UV-vis absorbance of SRFA between 250 and $400 \mathrm{~nm}$, and of decreased TOC (Figure S3 and Table S5). Formulas of chlorine-containing OBCs were also found in AFW samples, which might be the reaction products from $\mathrm{Cl}^{-}$in the $\mathrm{HCl}$ used for acidifying the samples prior to SPE. ${ }^{36}$ The OBCs formed under natural sunlight illumination in AFW and ASW, especially for OBCs$2 \mathrm{Br}$, were greatly reduced as compared to the corresponding OBCs in simulated sunlight irradiation. This might be associated with the higher intensity and greater UV component of natural sunlight (Figure S1), which can cause the photodegradation of newly formed OBCs. ${ }^{49-52}$ It should be noted that theoretically the formation of OBCs is not favorable in dark environments and even in light irradiation environments due to the high redox potential of bromine $\left(E^{\Theta}\left(\mathrm{Br}_{2} /\right.\right.$ $\left.\left.\mathrm{Br}^{-}\right)=1.07 \mathrm{~V}\right)$. These various bromine-containing compounds detected by ESI-FT-ICR MS and subsequent MS spectra interpretation need further verification, which might be realized by development of more accurate data processing methods to consistently and objectively assign peaks.

The van Krevelen diagram and Kendrick diagram can provide a visual display of compound distribution and composition. ${ }^{31,43}$ As shown in Figure 2A, the OBCs formed in freshwater and seawater sample under simulated sunlight irradiation showed a similar $\mathrm{H} / \mathrm{C}$ and $\mathrm{O} / \mathrm{C}$ range, which was more diverse compared to the OBCs generated under dark environment $(\mathrm{H} / \mathrm{C}$ ratios ca. $0.5-1.2$ and $\mathrm{O} / \mathrm{C}$ ratios of ca. $0.1-0.2, \mathrm{H} / \mathrm{C}$ ratios ca. $1.7-$ 2.2 and $\mathrm{O} / \mathrm{C}$ ratios of ca. $0.1-0.5$, Figure S4). One interesting finding is that the $\mathrm{H} / \mathrm{C}$ range and $\mathrm{O} / \mathrm{C}$ range occupied by OBCs-2Br were ca. $1.5-2.2$ and ca. $0.1-0.5$, respectively, which are typical for lipid-like and protein-derived-like compounds containing an unsaturated double bond $\mathrm{d}^{53,54}$ and suggests a possible addition reaction between the RBrS and DOM. The modified Kendrick analysis (as shown in Figure S5) revealed several homologous series of OBCs, suggesting high degrees of similarity between these OBCs and unbrominated SRFA. ${ }^{55}$ The majority of OBCs were detected between 400 and $700 \mathrm{Da}$. The OBCs produced under natural and simulated sunlight illumination showed similar distribution and composition (Figure S6 and S7).

It is well-known that $\mathrm{RBrS}$ reacts with $\mathrm{DOM}$ mainly via addition reaction (AR) and substitution reaction (SR). Thus, we replaced $\mathrm{Br}$ with hydrogen to revert the molecule to the one that only contains $\mathrm{C}, \mathrm{H}$, and $\mathrm{O}^{40}$ and compared it with unbrominated SRFA. All the OBCs can be divided into three categories according to the reaction type. It had been previously delineated that various groups of organic compounds are plotted in certain regions of the van Krevelen diagram. Herein all the identified molecules were classified into five groups based on their molecular composition as described in Materials and Methods by using $\mathrm{AI}$ mod and $\mathrm{H} / \mathrm{C}$ ratio. As shown in Figure 2, over $89 \%$ of $\overline{\mathrm{OBCs}}$ (Table S4) under simulated sunlight irradiation in freshwater and seawater was via $\mathrm{SR}$ or AR accompanied by other reactions (SAOR, Table S4). Most of these compounds were unsaturated aliphatic compounds (group 4) and saturated fatty and carbohydrates (group 5) including lipid, protein, amino-sugars, and cellulose. A smaller number of compounds were condensed polycyclic aromatics (group 1) and polyphenols (group 2) with relatively little oxygen $(\mathrm{O} / \mathrm{C}<0.2)$, which were recognized as unsaturated hydrocarbons comprising a mixture of aliphatic, aromatic, and alkene compounds. ${ }^{56}$

The OBCs under natural sunlight radiation (Table S4) were also formed mainly via SAOR (over $80 \%$ ), but with declined proportion, and second via direct substitution reaction (SR, more than 14\%) compared to the corresponding OBCs formed under simulated light illumination. Unlike the OBCs generated under simulated sunlight irradiation (Figure S6), the majority 


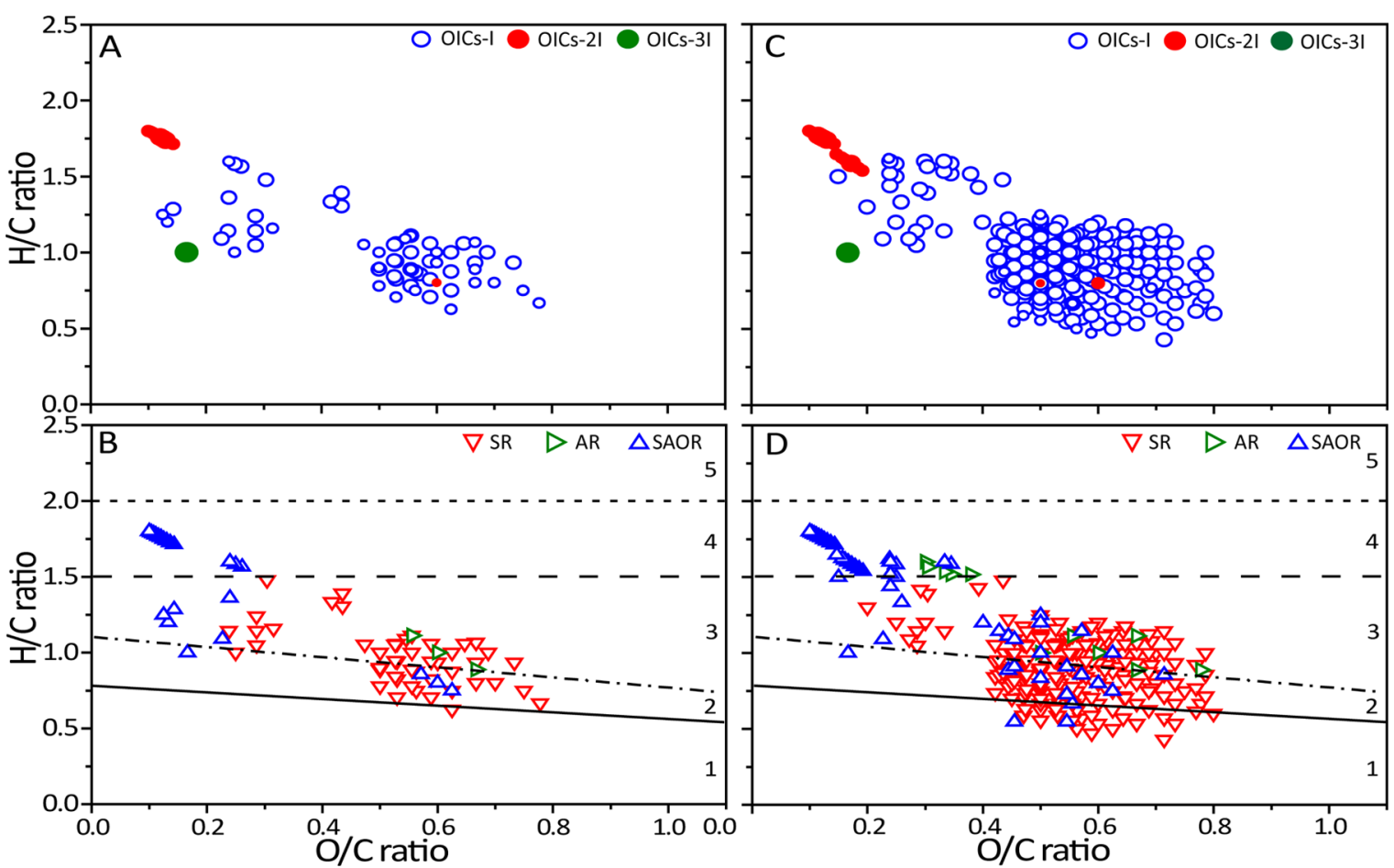

Figure 4. Molecular composition of OICs in photoiodinated AFW and ASW samples under simulated sunlight radiation. (A, C) van Krevelen diagram for OICs in AFW and ASW samples, respectively. (B, D) van Krevelen diagram for OICs in AFW and ASW samples formed via different reaction pathways, respectively. The bubble sizes for $\mathrm{A}$ and $\mathrm{C}$ represent the relative abundance of ions.

were highly unsaturated and phenolic compounds (group 3) showing a large increase from $2 \%$ to $18 \%$ for AFW and $6 \%$ to $25 \%$ for ASW, as well as aliphatic compounds (group 4) and saturated and carbohydrates (group 5). The OBCs in groups 1 and 2 decreased, indicating photodegradation of the unsaturated hydrocarbons and the generation of more brominecontaining aromatic compounds was favored under the natural sunlight illumination.

Sunlight-Driven lodination of DOM in AFW and ASW. Compared with bromide ion, iodide ion could be more easily oxidized by ROS and ${ }^{3} \mathrm{DOM}^{*}$ to RIS and further incorporated into DOM to form OICs. ${ }^{22,23}$ Experiments to investigate the iodination of DOM were performed on solutions of SRFA in AFW and ASW illuminated with simulated and natural solar light, and an ESI-FT-ICR MS comparison of the SRFA of the dark control versus light radiation water revealed the generation of various OICs (Figure 3 and Figure S8). In total, 39, 74, and 32 OICs were identified in AFW under dark environment and simulated and natural sunlight radiation, and 45, 253, and 113 OICs were identified in ASW under the corresponding conditions, respectively. The vast majority were one-iodinecontaining compounds (OICs-I, Table S6). Detailed molecular formulas for these iodine-containing components are listed in Table S10 and S11. In the replicated experiment for ASW photoiodination under simulated sunlight irradiation, 242 OICs were identified with compositional distribution similar to those of the 253 OICs detected in previous DOM photoiodination in ASW. The detection of OICs produced under the dark environment indicated the dark formation of RIS in the presence of DOM. Among these OICs formed in the dark environment, only 15 and 6 OICs overlapped with that formed in AFW under simulated and natural sunlight radiation, respectively. The average peak intensity of these overlapped compounds increased by $20 \%$ under simulated sunlight radiation and decreased by $18 \%$ under natural sunlight radiation. It is important to note that this comparison could not reveal real changes in content because FT-ICR MS is qualitative and various factors could affect the peak intensities. Seven and zero OICs formed in darkness overlapped with that formed in ASW under simulated and natural sunlight radiation, respectively, suggesting the dual function of enhancing formation and degradation by light illumination. The OICs formed under natural sunlight irradiation were greatly reduced (SI Table S6), especially for the OICs containing two iodine atoms (OICs-2I) that were no longer detected. This might be ascribed to the low $\mathrm{C}-\mathrm{I}$ bond dissociation energies $(209 \mathrm{~kJ}$ $\mathrm{mol}^{-1}$ ) that made it more susceptible to photodegradation. ${ }^{57}$ More OICs were formed in ASW than in AFW, regardless of light source, which possibly resulted from mixed halogen species like such as $\mathrm{ICl}^{--}$and/or $\mathrm{ICl}$. This inference was confirmed by the detection of organic compounds containing both chlorine and iodine (Table S7), which once again supports that seawater-level chloride ion plays a significant role in driving photohalogenation.

The formulas of OICs in freshwater and seawater under simulated solar radiation had $\mathrm{H} / \mathrm{C}$ ratios of $\sim 0.4-1.8$ and $\mathrm{O} / \mathrm{C}$ ratios of $\sim 0.1-0.8$, which were similar to the OICs formed in the dark but narrower as compared to the $\mathrm{H} / \mathrm{C}$ ratios and $\mathrm{O} / \mathrm{C}$ ratios of OBCs (Figure 4). Likewise, the $\mathrm{CH}_{2}$-based modified Kendrick analysis (Figure S10) revealed that the OICs produced were composed of several $\mathrm{CH}_{2}$ homologous series, which is in accordance with the classic structure of SRFA. ${ }^{31}$ The mass range occupied by OICs was mainly between 250 and $700 \mathrm{Da}$. The distribution trend and composition of OICs formed under simulated and natural sunlight radiation were similar (Figure S10-S11), and the vast majority of them were distributed in the regions of $\mathrm{H} / \mathrm{C}$ ratios of $\sim 0.4-1.5$ and $\mathrm{O} / \mathrm{C}$ ratios of $\sim 0.4-0.8$. 
All the OICs, likewise, were classified into three categories based on reaction type by replacing iodine with hydrogen and comparing with the uniodinated SRFA. ${ }^{40}$ Figure $4 \mathrm{~B}$ and $4 \mathrm{D}$ visually shows the distribution of OICs derived from different pathways under simulated sunlight radiation. The results indicate that the OICs were formed primarily through SR (65\% for AFW and 75\% for ASW) and through SAOR (31\% for AFW and $21 \%$ for ASW). This was quite different from the OICs formed in the dark, which were generated mainly through SAOR ( $72 \%$ for AFW and $76 \%$ for ASW). The OICs formed in the dark were mainly located in the $\mathrm{H} / \mathrm{C}$ ratio range of $\sim 0.4-$ 1.8 and $\mathrm{O} / \mathrm{C}$ ratio range of $\sim 0.1-0.8$ (Figure S9), probably containing hydroxyl (HO-Aryl) or ester moieties ( $\mathrm{C}-\mathrm{O}-\mathrm{C}$ ). These compounds might be easily subject to phototransformation, as evidenced by the large decrease in the number of compounds in this region after solar radiation (Figures 4, S9, and S11). More interestingly, the OICs were mainly clustered in group 3, group 2, and group 4, which are typical for ligninlike and tannin-like compounds, indicating that these compounds contained aromatic structures. Similarly, the new OICs that formed under natural solar irradiation were mainly via SR (59\% for AFW and 84\% for ASW, as shown Figure S11), and group 2 and group 3 were the major components of the newly produced OICs, suggesting a reaction mechanism similar to that of DOM iodination under simulated solar illumination.

Comparison of Photochemical Bromination and lodination. The above results show that light irradiation plays significant roles in both the formation and degradation of OBCs and OICs, as evidenced by the enhancement and reduction of the formation of photohalogenated products, as well as the decrease in intensity of the overlapped peaks in freshwater under natural solar irradiation. However, the OBCs formed under sunlight radiation were mainly unsaturated hydrocarbons with low $\mathrm{O} / \mathrm{C}$ ratio and high $\mathrm{H} / \mathrm{C}$ ratios, including unsaturated aliphatic compounds and saturated fatty compounds. These compounds are electron-rich organic molecules containing unsaturated moieties, rendering them highly susceptible to bromination. ${ }^{14,58}$ Moreover, these compounds probably make up part of the photolabile and photoproduced carbon pool that can be easily decomposed or produced over a period of days or years. ${ }^{59}$ Accordingly, it is reasonable to infer that other reactions such as oxidation or degradation had occurred before, after, and/or during bromination processes. These results demonstrate the effectiveness of the proposed methods for classifying the newly produced OBCs through these three reaction pathways. Most of the OBCs formed through SR ( $\mathrm{H} / \mathrm{C}$ ratios of $\sim 0.9-1.6$ and $\mathrm{O} / \mathrm{C}$ ratios of $\sim 0.2-0.5)$ after $7 \mathrm{~d}$ of sunlight radiation were similar to lignin-like compounds, suggesting the photostability of these compounds.

The cluster analysis results showed that three groups of halogenated samples were characterized under different experimental conditions, and a high degree of dissimilarity existed between OBCs and OICs (SI Figure S13), which might be related to the total difference between OIC and OBCs in distribution and composition patterns. The major differences between OIC and OBCs were reflected in three aspects: first, OICs-I were the primary components; second, OICs formed mainly via SR; third, nearly all OICs were lignin-like compounds comprising polyphenolic oligomers and hemicellulose polymers $^{56}$ and/or carboxylic-rich alicyclic molecules (double bond equivalent (DBE): $\mathrm{C}=0.30-0.68, \mathrm{DBE}: \mathrm{H}=$ $0.20-0.95$, DBE:O $=0.77-1.75)$ composed of a complex mixture of carboxylic and alicyclic compounds, which have been previously reported as one of the major refractory components of DOM. ${ }^{60}$ The compounds in this region might contain functional groups on aromatic structures, such as esterified products of phenolic and formic acids or other aliphatic carboxylic acids, which rendered the $\pi$ system of the aromatic ring more nucleophilic for iodine electrophilic substitution. ${ }^{13,61}$ Although Bateman et al. proved the formation of esters due to reaction of carboxylic acid groups with methanol, ${ }^{62}$ such a case was not observed in our experiments. Hemicellulose-lignin-like structures connecting the hemicellulose polymers and lignin polymers through phenyl-glycosidic-linkages would be also favorable for iodine to bind to DOM substances. ${ }^{13}$ Peaks assigned to the region of lignin-like and CRAM compounds should contain an aromatic structure because RIS is not reactive toward hydrocarbons such as aliphatic compounds, alkenes, and alkynes. $^{63}$ These compounds are regarded to be quite stable and can only be broken by strong nucleophiles. In addition, a molecular conformation containing a hydrophobic aliphatic periphery might hinder the accessibility of active cores to iodine, ${ }^{13}$ therefore, the vast majority of OICs had higher O/C ratios. This finding is of great importance because halophenolic compounds generally had toxicity higher than that of the commonly known haloacetic acids, and iodinated compounds were more toxic than their brominated and chlorinated analogues. $^{64}$

Environmental Implications. DOM is a ubiquitous component of natural surface waters and can be an important precursor for natural organohalogen compounds. ${ }^{18,53}$ We have shown that sunlight radiation can indeed promote the generation of $\mathrm{OBC}$ and $\mathrm{OIC}$ compounds as well as partially degrade the newly formed OBCs and OICs in freshwater and seawater, which might play an important role in halogen biogeochemical cycling. In addition, these OBCs and OICs generally have toxicity higher than that of their chlorinated analogues ${ }^{4-7,65}$ and deserve more attention. ${ }^{64}$ With the application of FT-ICR MS, valuable information about the molecular compositions and structures of OBCs and OICs could be provided. More detailed study is necessary to explore the photochemical mechanism of the organohalogen formation and to investigate the controlling factors of natural $\mathrm{OBC}$ and OIC generation in freshwater and seawater. Meanwhile, the formation of OBCs and OICs in a dark environment should not be ignored, and further work should focus on assessing the importance of them in halogen biogeochemical cycling, as well as their formation mechanism and fate in the natural environment. Furthermore, there is a pressing need to get accurate structure and concentration information and improve our knowledge on the unknown natural $\mathrm{OBCs}$ and OICs; therefore, new analytical methods should be developed with the help of offline or online chromatographic preconcentration and preseparation. Besides all the above, the risk of the naturally generated OBCs and OICs within natural waters should be further investigated.

\section{ASSOCIATED CONTENT}

\section{Supporting Information}

The Supporting Information is available free of charge on the ACS Publications website at DOI: 10.1021/acs.est.6b03887.

Additional information as noted in text (PDF) 


\section{AUTHOR INFORMATION}

\section{Corresponding Author}

*E-mail: jfliu@rcees.ac.cn. Tel.: +86-10-62849192. Fax: +8610-62849192.

ORCID $\odot$

Dong Cao: 0000-0001-8793-4401

Jingfu Liu: 0000-0001-7134-7026

Notes

The authors declare no competing financial interest.

\section{ACKNOWLEDGMENTS}

We thank Prof. Xuejun Pan at Kunming University of Science and Technology for providing a place for natural illumination experiments. This work was supported by the National Key Research and Development Program of China (2016YFA0203102), the Strategic Priority Research Program of the Chinese Academy of Sciences (XDB14020101), and the National Natural Science Foundation of China (21377156, 21337004).

\section{REFERENCES}

(1) Gallard, H.; Allard, S.; Nicolau, R.; von Gunten, U.; Croué, J. P. Formation of iodinated organic compounds by oxidation of iodidecontaining waters with manganese dioxide. Environ. Sci. Technol. 2009, 43 (18), 7003-7009.

(2) Leri, A. C.; Hakala, J. A.; Marcus, M. A.; Lanzirotti, A.; Reddy, C. M.; Myneni, S. C. B. Natural organobromine in marine sediments: New evidence of biogeochemical Br cycling. Global Biogeochem. Cycles 2010, 24 (4), GB4017.

(3) Gribble, G. W. Naturally occurring organohalogen compounds - A comprehensive update; Springer-Verlag: Vienna, 2010; Vol. 91.

(4) Richardson, S. D.; Plewa, M. J.; Wagner, E. D.; Schoeny, R.; DeMarini, D. M. Occurrence, genotoxicity, and carcinogenicity of regulated and emerging disinfection by-products in drinking water: A review and roadmap for research. Mutat. Res., Rev. Mutat. Res. 2007, $636(1-3), 178-242$.

(5) Komaki, Y.; Pals, J.; Wagner, E. D.; Mariñas, B. J.; Plewa, M. J. Mammalian cell DNA damage and repair kinetics of monohaloacetic acid drinking water disinfection byproducts. Environ. Sci. Technol. 2009, 43 (21), 8437-8442.

(6) Plewa, M. J.; Wagner, E. D.; Richardson, S. D.; Thruston, A. D.; Woo, Y.-T.; McKague, A. B. Chemical and biological characterization of newly discovered iodoacid drinking water disinfection byproducts. Environ. Sci. Technol. 2004, 38 (18), 4713-4722.

(7) Richardson, S. D.; Fasano, F.; Ellington, J. J.; Crumley, F. G.; Buettner, K. M.; Evans, J. J.; Blount, B. C.; Silva, L. K.; Waite, T. J.; Luther, G. W.; McKague, A. B.; Miltner, R. J.; Wagner, E. D.; Plewa, $\mathrm{M}$. J. Occurrence and mammalian cell toxicity of iodinated disinfection byproducts in drinking water. Environ. Sci. Technol. 2008, 42 (22), $8330-8338$.

(8) Gribble, G. W. The diversity of naturally produced organohalogens. Chemosphere 2003, 52 (2), 289-297.

(9) Wang, L.; Zhou, X.; Fredimoses, M.; Liao, S.; Liu, Y. Naturally occurring organoiodines. RSC Adv. 2014, 4 (101), 57350-57376.

(10) Gribble, G. W. Naturally occurring organohalogen compounds. Acc. Chem. Res. 1998, 31 (3), 141-152.

(11) Martino, M.; Mills, G. P.; Woeltjen, J.; Liss, P. S. A new source of volatile organoiodine compounds in surface seawater. Geophys. Res. Lett. 2009, 36 (1), L01609.

(12) Allard, S.; Gallard, H. Abiotic formation of methyl iodide on synthetic birnessite: A mechanistic study. Sci. Total Environ. 2013, 463-464 (0), 169-175.

(13) Xu, C.; Zhong, J.; Hatcher, P. G.; Zhang, S.; Li, H.-P.; Ho, Y.-F.; Schwehr, K. A.; Kaplan, D. I.; Roberts, K. A.; Brinkmeyer, R.; Yeager, C. M.; Santschi, P. H. Molecular environment of stable iodine and radioiodine $\left({ }^{129} \mathrm{I}\right)$ in natural organic matter: Evidence inferred from
NMR and binding experiments at environmentally relevant concentrations. Geochim. Cosmochim. Acta 2012, 97, 166-182.

(14) Leri, A. C.; Ravel, B. Abiotic bromination of soil organic matter. Environ. Sci. Technol. 2015, 49 (22), 13350-13359.

(15) Anastasio, C.; Matthew, B. M. A chemical probe technique for the determination of reactive halogen species in aqueous solution: Part 2 - Chloride solutions and mixed bromide/chloride solutions. Atmos. Chem. Phys. 2006, 6 (9), 2439-2451.

(16) Calza, P.; Massolino, C.; Pelizzetti, E.; Minero, C. Solar driven production of toxic halogenated and nitroaromatic compounds in natural seawater. Sci. Total Environ. 2008, 398 (1-3), 196-202.

(17) Tamtam, F.; Chiron, S. New insight into photo-bromination processes in saline surface waters: The case of salicylic acid. Sci. Total Environ. 2012, 435-436 (0), 345-350.

(18) Méndez-Díaz, J. D.; Shimabuku, K. K.; Ma, J.; Enumah, Z. O.; Pignatello, J. J.; Mitch, W. A.; Dodd, M. C. Sunlight-driven photochemical halogenation of dissolved organic matter in seawater: A natural abiotic source of organobromine and organoiodine. Environ. Sci. Technol. 2014, 48 (13), 7418-7427.

(19) Marchisio, A.; Minella, M.; Maurino, V.; Minero, C.; Vione, D. Photogeneration of reactive transient species upon irradiation of natural water samples: Formation quantum yields in different spectral intervals, and implications for the photochemistry of surface waters. Water Res. 2015, 73 (0), 145-156.

(20) Richard, C.; Canonica, S., Aquatic phototransformation of organic contaminants induced by coloured dissolved natural organic matter. in Environmental Photochemistry Part II; Boule, P.; Bahnemann, D. W.; Robertson, P. K. J., Eds.; Springer: Berlin, 2005; pp 299-323.

(21) Jammoul, A.; Dumas, S.; D’Anna, B.; George, C. Photoinduced oxidation of sea salt halides by aromatic ketones: a source of halogenated radicals. Atmos. Chem. Phys. 2009, 9 (13), 4229-4237.

(22) Mopper, K.; Zhou, X. Hydroxyl radical photoproduction in the sea and its potential impact on marine processes. Science 1990, 250 (4981), 661-664.

(23) Reeser, D. I.; George, C.; Donaldson, D. J. Photooxidation of halides by chlorophyll at the air-salt water interface. J. Phys. Chem. A 2009, 113 (30), 8591-8595.

(24) De Laurentiis, E.; Minella, M.; Maurino, V.; Minero, C.; Mailhot, G.; Sarakha, M.; Brigante, M.; Vione, D. Assessing the occurrence of the dibromide radical $\left(\mathrm{Br}_{2}^{-}\right)$in natural waters: Measures of triplet-sensitised formation, reactivity, and modelling. Sci. Total Environ. 2012, 439 (0), 299-306.

(25) Saunders, R. W.; Kumar, R.; MacDonald, S. M.; Plane, J. M. C. Insights into the photochemical transformation of iodine in aqueous systems: Humic acid photosensitized reduction of iodate. Environ. Sci. Technol. 2012, 46 (21), 11854-11861.

(26) Zhang, P.; Sun, D. Q.; Wen, M. W.; Yang, J. K.; Zhou, K. B.; Wang, Z. X. Hydroxyl radical promotes the direct iodination of aromatic compounds with iodine in water: A combined experimental and theoretical study. Adv. Synth. Catal. 2012, 354 (4), 720-729.

(27) Moore, R. M.; Zafiriou, O. C. Photochemical production of methyl iodide in seawater. J. Geophys. Res. 1994, 99 (D8), 1641516420.

(28) Smith, E. M.; Plewa, M. J.; Lindell, C. L.; Richardson, S. D.; Mitch, W. A. Comparison of byproduct formation in waters treated with chlorine and iodine: Relevance to point-of-use treatment. Environ. Sci. Technol. 2010, 44 (22), 8446-8452.

(29) Heeb, M. B.; Criquet, J.; Zimmermann-Steffens, S. G.; von Gunten, U. Oxidative treatment of bromide-containing waters: Formation of bromine and its reactions with inorganic and organic compounds-A critical review. Water Res. 2014, 48 (0), 15-42.

(30) Grebel, J. E.; Pignatello, J. J.; Mitch, W. A. Effect of halide ions and carbonates on organic contaminant degradation by hydroxyl radical-based advanced oxidation processes in saline waters. Environ. Sci. Technol. 2010, 44 (17), 6822-6828.

(31) Stenson, A. C.; Marshall, A. G.; Cooper, W. T. Exact masses and chemical formulas of individual Suwannee River fulvic acids from ultrahigh resolution electrospray ionization fourier transform ion 
cyclotron resonance mass spectra. Anal. Chem. 2003, 75 (6), 12751284.

(32) Reemtsma, T.; These, A.; Linscheid, M.; Leenheer, J.; Spitzy, A. Molecular and structural characterization of dissolved organic matter from the deep ocean by FTICR-MS, including hydrophilic nitrogenous organic molecules. Environ. Sci. Technol. 2008, 42 (5), 1430-1437.

(33) Baluha, D. R; Blough, N. V.; Del Vecchio, R. Selective mass labeling for linking the optical properties of chromophoric dissolved organic matter to structure and composition via ultrahigh resolution electrospray ionization mass spectrometry. Environ. Sci. Technol. 2013, 47 (17), 9891-9897.

(34) Kellerman, A. M.; Dittmar, T.; Kothawala, D. N.; Tranvik, L. J. Chemodiversity of dissolved organic matter in lakes driven by climate and hydrology. Nat. Commun. 2014, 5, 8.

(35) Stubbins, A.; Spencer, R. G. M.; Chen, H.; Hatcher, P. G.; Mopper, K.; Hernes, P. J.; Mwamba, V. L.; Mangangu, A. M.; Wabakanghanzi, J. N.; Six, J. Illuminated darkness: Molecular signatures of Congo River dissolved organic matter and its photochemical alteration as revealed by ultrahigh precision mass spectrometry. Limnol. Oceanogr. 2010, 55 (4), 1467-1477.

(36) Lavonen, E. E.; Gonsior, M.; Tranvik, L. J.; Schmitt-Kopplin, P.; Köhler, S. J. Selective chlorination of natural organic matter: Identification of previously unknown disinfection byproducts. Environ. Sci. Technol. 2013, 47 (5), 2264-2271.

(37) Zhang, H.; Zhang, Y.; Shi, Q.; Hu, J.; Chu, M.; Yu, J.; Yang, M. Study on transformation of natural organic matter in source water during chlorination and its chlorinated products using ultrahigh resolution mass spectrometry. Environ. Sci. Technol. 2012, 46 (8), 4396-4402.

(38) Zhang, H.; Zhang, Y.; Shi, Q.; Ren, S.; Yu, J.; Ji, F.; Luo, W.; Yang, M. Characterization of low molecular weight dissolved natural organic matter along the treatment trait of a waterworks using Fourier transform ion cyclotron resonance mass spectrometry. Water Res. 2012, 46 (16), 5197-5204.

(39) Zhang, H.; Zhang, Y.; Shi, Q.; Zheng, H.; Yang, M. Characterization of unknown brominated disinfection byproducts during chlorination using ultrahigh resolution mass spectrometry. Environ. Sci. Technol. 2014, 48 (6), 3112-3119.

(40) Xu, C.; Chen, H.; Sugiyama, Y.; Zhang, S.; Li, H.-P.; Ho, Y.-F.; Chuang, C.-y.; Schwehr, K. A.; Kaplan, D. I.; Yeager, C.; Roberts, K. A.; Hatcher, P. G.; Santschi, P. H. Novel molecular-level evidence of iodine binding to natural organic matter from Fourier transform ion cyclotron resonance mass spectrometry. Sci. Total Environ. 2013, 449, 244-252.

(41) Dittmar, T.; Koch, B.; Hertkorn, N.; Kattner, G. A simple and efficient method for the solid-phase extraction of dissolved organic matter (SPE-DOM) from seawater. Limnol. Oceanogr.: Methods 2008, $6,230-235$.

(42) Gonsior, M.; Schmitt-Kopplin, P.; Stavklint, H.; Richardson, S. D.; Hertkorn, N.; Bastviken, D. Changes in dissolved organic matter during the treatment processes of a drinking water plant in sweden and formation of previously unknown disinfection byproducts. Environ. Sci. Technol. 2014, 48 (21), 12714-12722.

(43) Shakeri Yekta, S.; Gonsior, M.; Schmitt-Kopplin, P.; Svensson, B. H. Characterization of dissolved organic matter in full scale continuous stirred tank biogas reactors using ultrahigh resolution mass spectrometry: A qualitative overview. Environ. Sci. Technol. 2012, 46 (22), 12711-12719.

(44) Kim, S.; Kramer, R. W.; Hatcher, P. G. Graphical method for analysis of ultrahigh-resolution broadband mass spectra of natural organic matter, the Van Krevelen Diagram. Anal. Chem. 2003, 75 (20), 5336-5344.

(45) Koch, B. P.; Dittmar, T. From mass to structure: an aromaticity index for high-resolution mass data of natural organic matter. Rapid Commun. Mass Spectrom. 2006, 20 (5), 926-932.

(46) Šantl-Temkiv, T.; Finster, K.; Dittmar, T.; Hansen, B. M.; Thyrhaug, R.; Nielsen, N. W.; Karlson, U. G. Hailstones: A window into the microbial and chemical inventory of a storm cloud. PLoS One 2013, 8 (1), e53550.
(47) Grebel, J. E.; Pignatello, J. J.; Song, W.; Cooper, W. J.; Mitch, W. A. Impact of halides on the photobleaching of dissolved organic matter. Mar. Chem. 2009, 115 (1-2), 134-144.

(48) Page, S. E.; Sander, M.; Arnold, W. A.; McNeill, K. Hydroxyl Radical Formation upon Oxidation of Reduced Humic Acids by Oxygen in the Dark. Environ. Sci. Technol. 2012, 46 (3), 1590-1597.

(49) Abusallout, I.; Hua, G. Natural solar photolysis of total organic chlorine, bromine and iodine in water. Water Res. 2016, 92, 69-77.

(50) Kohn, T.; Nelson, K. L. Sunlight-Mediated Inactivation of MS2 Coliphage via Exogenous Singlet Oxygen Produced by Sensitizers in Natural Waters. Environ. Sci. Technol. 2007, 41 (1), 192-197.

(51) Niu, X.-Z.; Liu, C.; Gutierrez, L.; Croué, J.-P. Photobleachinginduced changes in photosensitizing properties of dissolved organic matter. Water Res. 2014, 66 (0), 140-148.

(52) Sharpless, C. M.; Aeschbacher, M.; Page, S. E.; Wenk, J.; Sander, M.; McNeill, K. Photooxidation-induced changes in optical, electrochemical, and photochemical properties of humic substances. Environ. Sci. Technol. 2014, 48 (5), 2688-2696.

(53) Kujawinski, E. B.; Longnecker, K.; Blough, N. V.; Vecchio, R. D.; Finlay, L.; Kitner, J. B.; Giovannoni, S. J. Identification of possible source markers in marine dissolved organic matter using ultrahigh resolution mass spectrometry. Geochim. Cosmochim. Acta 2009, 73 (15), 4384-4399.

(54) Kim, S.; Kaplan, L. A.; Hatcher, P. G. Biodegradable dissolved organic matter in a temperate and a tropical stream determined from ultra-high resolution mass spectrometry. Limnol. Oceanogr. 2006, 51 (2), 1054-1063.

(55) Gonsior, M.; Mitchelmore, C.; Heyes, A.; Harir, M.; Richardson, S. D.; Petty, W. T.; Wright, D. A.; Schmitt-Kopplin, P. Bromination of marine dissolved organic matter following full scale electrochemical ballast water disinfection. Environ. Sci. Technol. 2015, 49 (15), 90489055.

(56) Hockaday, W. C.; Purcell, J. M.; Marshall, A. G.; Baldock, J. A.; Hatcher, P. G. Electrospray and photoionization mass spectrometry for the characterization of organic matter in natural waters: A qualitative assessment. Limnol. Oceanogr.: Methods 2009, 7 (1), 81-95.

(57) Wong, G. T. F.; Cheng, X. H. The formation of iodide in inshore waters from the photochemical decomposition of dissolved organic iodine. Mar. Chem. 2001, 74 (1), 53-64.

(58) Leri, A. C.; Mayer, L. M.; Thornton, K. R.; Ravel, B. Bromination of marine particulate organic matter through oxidative mechanisms. Geochim. Cosmochim. Acta 2014, 142, 53-63.

(59) Stubbins, A.; Dittmar, T. Illuminating the deep: Molecular signatures of photochemical alteration of dissolved organic matter from North Atlantic Deep Water. Mar. Chem. 2015, 177 (2), 318324.

(60) Hertkorn, N.; Benner, R.; Frommberger, M.; Schmitt-Kopplin, P.; Witt, M.; Kaiser, K.; Kettrup, A.; Hedges, J. I. Characterization of a major refractory component of marine dissolved organic matter. Geochim. Cosmochim. Acta 2006, 70 (12), 2990-3010.

(61) Wang, H.; Wang, W.; Jin, W. J. $\sigma$-Hole Bond vs $\pi$-Hole Bond: A comparison based on halogen bond. Chem. Rev. 2016, 116, 50725104.

(62) Bateman, A. P.; Walser, M. L.; Desyaterik, Y.; Laskin, J.; Laskin, A.; Nizkorodov, S. A. The effect of solvent on the analysis of secondary organic aerosol using electrospray ionization mass spectrometry. Environ. Sci. Technol. 2008, 42 (19), 7341-7346.

(63) Simpson, W. R.; Brown, S. S.; Saiz-Lopez, A.; Thornton, J. A.; Glasow, R. v. Tropospheric halogen chemistry: Sources, cycling, and impacts. Chem. Rev. 2015, 115 (10), 4035-4062.

(64) Liu, J.; Zhang, X. Comparative toxicity of new halophenolic DBPs in chlorinated saline wastewater effluents against a marine alga: Halophenolic DBPs are generally more toxic than haloaliphatic ones. Water Res. 2014, 65 (0), 64-72.

(65) Yang, Y.; Komaki, Y.; Kimura, S. Y.; Hu, H.-Y.; Wagner, E. D.; Mariñas, B. J.; Plewa, M. J. Toxic impact of bromide and iodide on drinking water disinfected with chlorine or chloramines. Environ. Sci. Technol. 2014, 48 (20), 12362-12369. 